\title{
Health literacy in COPD
}

\author{
Nicola J Roberts \\ Ramesh Ghiassi \\ Martyn R Partridge \\ Department of Respiratory Medicine, \\ $\mathrm{NHLI}$ at Charing Cross Hospital, \\ Imperial College London, UK
}

\begin{abstract}
If patients are to participate fully in their care and in the management of a long term condition such as chronic obstructive pulmonary disease, good communication is essential. However, not all patients are able to use the written word and we need to be aware of the size of this problem and its implications for the way in which we give information and conduct medical consultations. The impact of health literacy on outcomes can be considerable and improvements can be made by being aware of the problem, offering information in several different forms, and by reinforcing the spoken word with pictorial images.

Keywords: health literacy, reading, compliance, pictograms, communication, consultations
\end{abstract}

\section{Introduction}

Good communication is essential within the healthcare system. If patient centered care is to be developed within a partnership of care between a patient and a healthcare professional, the sharing of medical information needs to be fully comprehensible by all. This necessitates an awareness of the range of literacy skills possessed by our patients, the impact of reduced health literacy skills and its impact upon access to healthcare. In this review we have addressed the size of the problem, its identification, its impact, and how to minimize the effect of reduced health literacy.

\section{What is health literacy?}

Health literacy is defined as the ability to read, understand and act on health care information. In more detail, health literacy is the degree to which individuals have the capacity to obtain, process and understand basic health information and services required to make appropriate health decisions (US Department of Health and Human Services 2000). According to the United States (US) National Adult Literacy Survey (NALS) in 1992, 21\% of those surveyed in the US scored in the lowest of 5 skill levels (Kirsch et al 1993). In the UK approximately 16\% of adults have literacy skills lower than that attained by the average 11 year old (The Skills for Life Survey 2003).

Diminished health literacy is a widespread problem which affects people of all social classes and all ethnic groups. Impaired health literacy has been shown to be worse amongst the elderly and amongst low-income populations (Wolf et al 2005) and more recently, the 2003 National Assessment of Adult Literacy has shown that, more than 75 million adults in the US have only basic or less than basic health literacy (Kutner 2006). A US systematic review of 85 studies showed there was no association with gender but a positive association with level of education, ethnicity and age (Paasche-Orlow et al 2005). This may or may not be the same in other countries.

In terms of how this relates to how patients manage their care, one study looked at how much patients understand about taking their medication and showed that between $67.1 \%$ and $91.1 \%$ of patients surveyed correctly understood the medicine label instructions, with those with the lowest literacy scoring the lowest (Davis et al 2006). Just over a third could say how many tablets should be taken when given a 
written label containing the instructions "Take two tablets by mouth twice daily".

Patients with limited health literacy skills have been shown to report poorer overall health and they are less likely to make use of screening and they present in later stages of disease. They are more likely to be hospitalized, have an overall poorer understanding of their treatment and have lower adherence to medical regimens (Centre for Health Care Strategies 2008).

Studies in a less wealthy population suggest that patients with low health literacy skills and chronic diseases such as diabetes, asthma, or hypertension have less knowledge of their disease and its treatment, as well as fewer correct self management skills than literate patients (Williams et al 1998a). Low health literacy is independently associated with poor understanding of disease (Williams et al 1998b), worse health status (Weiss BD 1992; Schillinger et al 2002), and higher use of services. (Baker et al 1997, 1998).

Low literacy affects all aspects of patients' lives and 40\% have been reported to express feelings of shame with two thirds not telling spouses of their literacy problems and over half never telling their children (Parikh et al 1996).

\section{Health literacy in the elderly}

Tests of literacy such as the Rapid Estimate of Adult Literacy in Medicine tool (REALM) assess the reading ability of individuals and are a crude measure of health literacy. This has been used to identify likely reduced health literacy skills in several patient groups. Among 127 patients attending a UK hospital clinic with rheumatoid arthritis $15 \%$ were found to have functional illiteracy (Gordon et al 2002). Among those attending an US asthma clinic 13\% read at below 3rd grade (Williams et al 1998a). In a UK outpatient study of COPD patients $15 \%$ of patients were not able to use written information (Taylor et al 2005).

Other studies have shown lower reading skills in older age groups (Gazmararian et al 1999). The NALS study showed that in those aged over 65 years, $44 \%$ had the lowest reading level compared to $16 \%$ in 45 to 54 age group. Further analysis of the data showed that $43.6 \%$ of the elderly in this study were taking more than 3 medications per day and $66.5 \%$ had at least one of five chronic conditions (COPD, coronary heart disease, heart failure, hypertension, or diabetes) (Kirsch et al 1993). Paasche-Orlow et al (2005) showed in a systematic review of 31,129 patients that a low level of health literacy correlated with reduced level of education, ethnicity and older age.
There are many factors which may explain the high incidence of reduced health literacy in elderly populations and conditions such as dementia and cognitive decline will clearly also affect an individual's health literacy. The incidence of dementia increases dramatically in older people (Hatcher 1999). Dementia affects approximately $6 \%$ of people at 65 years and approximately $24 \%$ of those over 85 years, although these figures are not consistently found (Henderson and Jorm 1998). Depression may also impair concentration and may be a risk factor for cognitive decline (Jorm 2000).

Poor reading skills have a very important impact on the elderly due to their high prevalence of chronic disease and their need to understand healthcare information. Patients with chronic conditions such as COPD are an important group to tackle because these patients typically have complex treatment regimens, requiring multiple consultations often with different clinicians.

\section{Adherence with COPD therapy}

The nature of the disease, the treatment, patient beliefs and expectations about therapy all combine to influence patient adherence to therapy (Horne and Weinman 1999). In COPD as in asthma, adherence can be low and is a significant risk factor for morbidity and mortality (Cochrane 1992). Studies in asthma and COPD have shown that adherence can be less than $50 \%$ of prescribed medication (Rand 2005). Patients are likely to under-use maintenance therapy and symptom relieving drugs are often over used (Hand and Bradley 1996). In a study investigating prescription refill adherence for asthma and COPD, over half of repeat prescriptions for inhaled corticosteroids dispensed to patients over 60 showed an undersupply suggesting that these patients are not using their prescriptions optimally (Krigsman et al 2007).

In addition to a general limitation of their ability to recall information, patients with reduced health literacy may inherently have more difficulty comprehending medical information. Such individuals are thus more likely to be non-compliant due to misunderstandings (Rand 2005). Much of what is said in any medical consultation is forgotten soon after it ends (Ley 1979), and in elderly COPD patients, cognitive impairment can be an additional barrier to comprehension (Allen and Ragab 2002). Large-scale studies have been performed in patients with hypoxemia and have shown impairments in abstract reasoning, memory and co-ordination of simple motor tasks (Prigatano et al 1983; Grant et al 1982, 1987).

There is also an increased risk of depression in COPD patients, up to 2.5 times greater for severe COPD when compared to patients in the control group (van Manen et al 2002). 
Many patients with COPD experience a strong sense of loss and feelings of hopelessness perceiving that they were told that "nothing could be done" or that the condition was "self inflicted" (Oliver 2001). The published literature has shown that patients may feel guilty or depressed about their condition and studies recognize that consultations should involve the patient in decision making (Booker 2005; Osman and Hyland 2005). A study of diabetics with poor health literacy showed that physicians very rarely checked patient recall of new concepts or explained them more clearly (Schillinger et al 2003).

However little work has been done to identify the impact of health literacy on compliance in COPD or its effect upon what patients do or do not do in a consultation. We have previously shown how patients do not fully understand the medical letters they receive (Roberts and Partridge 2006) and have tried to provide further information to patients to improve their understanding (Brown et al 2007). However, there is little published evidence regarding the modifying of consultations/guidelines for patients with COPD who might have cognitive problems or limited health literacy.

\section{Improving compliance - interventions and educational programmes}

Using asthma as an example, self management strategies have been used to increase medication adherence and may include disease education, self-monitoring, teaching, and checking inhaler technique and reinforcement. Many of these interventions have been shown to work in adults with asthma (Bailey et al 1990; Onyirimba et al 2003; Put et al 2003). In COPD Bourbeau et al (2003) showed a reduction in hospital utilization in patients with COPD following a complex intervention; they demonstrated a reduction in hospital admission for exacerbations of COPD by $39.8 \%$ and ER attendances by $41 \%$. This programme included education, a home exercise programme, support, an action plan including use of antibiotics and steroid tablets, and case management. In 2003 a Cochrane review by Monninkhof et al (2003) concluded that there was too little data to say that self management in COPD works, although of the 8 studies reviewed only 2 involved the patient receiving a written self management action plan. Using an action plan with COPD patients increases recognition of a severe exacerbation and increases use of antibiotics and oral steroids (Turnock et al 2005) and can reduce unscheduled primary care consultations and may reduce mortality (Sridhar et al 2008).
These studies have thus shown that by giving patients individualized advice and going through medication with patients along with other interventions such as pulmonary rehabilitation and case management can improve some outcomes. However advice needs to be tailored further to ensure comprehensibility by all and this may involve use of pictorial aids within action plans and use of other formats such as DVDs to reinforce important messages for patients to take home.

Acceptance of interventions such as rehabilitation also needs to be considered and how invitations are made may be critical. In a study of those with chronic obstructive pulmonary disease involving pulmonary rehabilitation, 120 of 297 suitable patients responded that they did not wish to take part in the trial. These patients were subsequently approached in a qualitative study to determine why they declined to take part in the study. The results revealed that several themes influenced patients' willingness or otherwise to take part in a research project involving pulmonary rehabilitation. Patients often found it difficult to get to the hospital, they did not understand the purpose or benefit of the research, and they had negative experiences of the hospital and also thought that the pulmonary rehabilitation component would be detrimental to their health (Taylor et al 2007). The role of health literacy was not addressed in this study but we need to ensure that information such as invitation letters are user friendly and at an appropriate reading age to ensure recruitment of all suitable patients.

\section{Consultations with patients}

Consultations can be stressful events for patients and take place in an environment which is often perceived to be unfamiliar. Most patients are interrupted by the doctor within 18 seconds of their opening statement (Beckman and Frankel 1984), even though another study has shown that the average spontaneous talking time uninterrupted was 92 seconds and more than three quarters of patients had finished talking within 2 minutes (Langewitz et al 2002).

Studies by Falvo and Tippy (1988) and Schillinger et al (2003) have shown that patients recall very little (less than $50 \%$ ) of what they are told about during their consultations and another study has shown that patients and doctors often have conflicting views regarding the key messages that should be taken away from a consultation (Parkin 2003). Even when information is given patients commonly complain that physicians do not provide understandable explanations (Ziegler et al 2001). For patients with low levels of functional health literacy this problem will be enhanced and thus may 
experience problems reading labels of medication, interpreting results, comprehending appointment or reading materials and conceptualizing risk. They will also have difficulty naming and describing their medications (Williams et al 1995).

Constantinidou and Baker (2002) showed that older adults learned better from visual presentations of information than by auditory presentations. Use of both written and verbal communication has been shown to be the most effective way of increasing patient understanding and compliance (Houts et al 1998, 2001, 2006). Consultations may thus be improved in several ways, for example by giving the patient written advice or information such as a leaflet with details of their individual medication (Sandler et al 1989). As part of the UK NHS plan (Department of Health 2000) letters being sent from a specialist to the patients' general practitioner are also offered to the patient. This provision of information can be developed further by dictating these letters in front of the patient both to reduce factual errors before they leave but also to again reinforce information by means of the spoken word (Lloyd 1997). However, patients often do not fully understand the medical terms detailed within the letters they receive and the letters to primary care physicians copied to patients have been shown to be quite difficult for patients to read (Roberts and Partridge 2006). We designed a respiratory glossary which can be used as a tool in aiding respiratory patients understanding of the letter being sent to their GP (Brown et al 2007). It is important that the magnitude of low health literacy in the population is recognized and instead of trying to identify these vulnerable patient groups, other methods should be used to reinforce the comprehensibility for all patients especially those with longterm conditions. These may include use of consultation tools such as decision aids, pictograms, leaflets, or videos (Partridge 1986; Plimpton and Root 1994; Delp and Jones 1996; Sechrest and Henry 1996; Houts et al 1998; Murphy et al 2000). Pictorial representations have been shown to improve recall of medical instructions in a clinical setting (Houts et al 1998) and pictograms have been shown to be an effective tool, enhancing consultations and aiding understanding (Houts et al 2006). Patients with long term conditions should always be helped to learn how to manage their own condition (Partridge 2005).

\section{Identifying patients with low health literacy}

Individuals may have low health literacy skills for a range of reasons such as a lack of educational opportunity, learning difficulties, or cognitive decline which is increased in older adults. Individuals with low health literacy are more likely to be unable to name their medication, frequently miss appointments or say they have forgotten their glasses, and are more likely attend with someone else who takes on the role of "surrogate reader". In a study of patients seeing resident physicians, only $50 \%$ of those with impaired health literacy were correctly identified by the doctor (Rogers et al 2006). Kelly and Haidet (2007) have shown that doctors overestimated patient literacy for $54 \%$ of African Americans, $11 \%$ of white non-Hispanics, and $36 \%$ of other patients.

Two tools have been widely used with patients to objectively measure health literacy levels. The first is the Rapid Estimate of Adult Literacy in Medicine (REALM) test (Davis et al 1993) which is medical-word recognition and pronunciation test. Patients read 3 lists of words which increase in complexity and patients score from 0 to 66 which translates to American school grade level. The second test is the "TOFHLA" test which is a test of functional health literacy in adults, measuring numeracy and reading comprehension (Baker 1999). These tests can range from taking a few minutes (REALM) to 20 minutes (TOFHLA) to undertake and the appropriateness of the test and time to administer should be considered when selecting a test. Their use would normally be for research purposes alone and they would not usually be administered in a busy clinical situation. These tools need to be used sensitively for they can be distressing to patients who feel they are being tested, and in clinical practice the realization of the size of the problem of functional illiteracy is the vital point so that other methods of communication are used to reinforce advice for all patients.

\section{Improving comprehension within consultations with those with COPD}

It is difficult to predict which patients have limited health literacy (Kelly and Haidet 2007) and (Rogers et al 2006) and screening literacy levels in every new patient is probably impractical as well as potentially distressing to some who may find it an affront to their dignity. We know from published studies that it is likely that a minimum of $15 \%$ of patients may have diminished literacy (Williams et al 1998a; Gordon et al 2002). Reports show that those with diminished literacy often conceal it from others, including close family members (Parikh et al 1996). When considering how to improve comprehension within the consultation an increased awareness that those with COPD may have diminished literacy is a good a starting place.

A positive relationship between patient and health worker is essential particularly as this group of patients commonly exhibit 
low self esteem, depression and guilt regarding a condition which may be perceived as self afflicted. Building patient empathy and pre-empting potential obstacles in communication can aid effective knowledge transfer and improve adherence to therapy regimens and self management plans (Korsch and Negrete 1972). The development of self management plans for COPD patients should be carried out in a partnership between the patient and the doctor or nurse specialist. Providing patients with individualized advice and explaining how to take and how to alter medication, along with other interventions such as pulmonary rehabilitation and regular follow-up can improve outcomes (Bailey et al 1990; Monninkhof et al 2003). Advice could be tailored further to ensure that it is suitable for all including those with low literacy by using pictorial aids such as pictorial action plans and using other formats such as DVDs to reinforce important messages for patients to take home.

Information materials which have a predominately written component should be tested for level of readability with tools such as the Flesch reading age and Kincaid Scale available on modern Microsoft word packages. In addition to readability testing, simple thought to ensuring text or pictures are of adequate size is important (Wallace et al 2006). Kessler et al have shown that COPD patients' understanding of the word "exacerbation" was poor, a term which you would expect most COPD patients to recognize. $59.2 \%$ of patients had never heard of the term or did not know what it meant, and only $2(1.6 \%)$ could explain its meaning correctly (Kessler et al 2006). Patients used alternative words such as shortness of breath, breathlessness, crisis or attack. Speaking plainly, using simple language and identifying the key take home messages you need to convey can be useful: better communication and education are fundamental to allowing patients with COPD to better understand and develop strategies to cope with their disease. In a recent editorial reviewing a COPD rehabilitation programme, it was reported that prior to entry into the programme many patients reported a lack of basic understanding about COPD and management of their condition. Some patients reported not knowing what their condition was called and primary care was criticized as a poor source of expertise, information and support (Jones 2007).

Designing the consultation to contain more open ended questions and asking patients to repeat and confirm medication instructions before leaving the consultation can help check that instructions have been understood (Schillinger et al 2003). Rather than instructing someone to take their medicine at $9 \mathrm{AM}$ or $9 \mathrm{PM}$ use the words morning or evening; 24-hour clock time scales can be confusing. In addition awareness of cultural differences that may affect communication ought to be noted. Nodding may mean 'no' in some cultures and in those in whom English language is limited, providing a translator or family member who can translate can be helpful. Drawing a simple diagram to explain an investigation or medication taking behaviors can be helpful.

Thought might be given to the use of literature and material pre and post consultation as well as during the consultation (Partridge 1999; Brown et al 2007). Using questionnaires either pre-consultation in the waiting room or posting out to patients at home can have some use in aiding the consultation. Although health professionals should be aware that patients with reduced health literacy may struggle to fill in the simplest questionnaire, such tools may enable the patient to seek clarification from a partner or confidant such that they enter the consultation better prepared. We have shown, for example, that among those with suspected sleep apnea syndrome the Epworth Sleepiness Scale (ESS), a worded tool that is designed to be self completed, was not easily understood by all (Ghiassi et al 2007a). Respondents were required to mark the likelihood of falling asleep with an answer ranging from 0 to 3 , yet $33.8 \%$ of new users and $15.7 \%$ of those who had used the scale previously made errors when completing the form and needed additional one to one assistance from staff. Common errors ranged from giving answers between scores, leaving questions blank, or ticking or marking answers with a cross. $5 \%$ of patients were upfront and reported problems with health literacy and $2.5 \%$ asked a family member or friend to fill in the form. Some who struggled to complete the form reported that they had left their spectacles at home, an excuse often used by those with impaired health literacy skills.

\section{Pictorial aids - their use and evaluation}

To help deliver key health messages, clinicians have a range of resources available to them ranging from the written word to pictorial aids and videos. Consultation aids such as those given in Table 1 are useful in reinforcing health information (Partridge 1999; Houts et al 1998, 2001, 2006). In particular for those with diminished health literacy it may be important to present information in a variety of ways. Confucius (and sometimes Napoleon) is attributed with saying 'A picture is worth a thousand words'. Advertisers have been coupling pictures and words for decades to aid the successful transfer of information. Pictures in medicine similarly have been shown to be a successful adjunct to both verbal and written medical information (Katz et al 2006).

A study by Dowse and Ehlers assessed understanding of "text only" or "text plus pictogram" labels on prescribed 
Table I Tools that reinforce advice and information given during the consultation

\begin{tabular}{ll}
\hline Improving comprehension in consultations \\
\hline $\begin{array}{l}\text { Written or pictorial } \\
\text { information materials }\end{array}$ & Posters, audiotapes, videos and DVDs \\
$\begin{array}{l}\text { Teaching of self management } \\
\text { skills }\end{array}$ & $\begin{array}{l}\text { Personalised written information on } \\
\text { medication regimens }\end{array}$ \\
$\begin{array}{l}\text { Dictating letters to referring } \\
\text { doctors in front of the patient }\end{array}$ & Copying letters to patients \\
$\begin{array}{l}\text { Telephone consultations and } \\
\text { reviews }\end{array}$ & Inter-appointment contacts/support \\
\hline
\end{tabular}

antibiotics in a female low literacy population. Adherence to therapy and understanding of medication instructions were improved in the group that received "text and pictograms" in contrast to "text only" labels (Dowse and Ehlers 2005). Indeed even amongst those with normal literacy levels, pictograms have been shown to enhance the recall and transfer of medical information (Houts et al 1998, 2001). Research indicates that humans have a cognitive preference for picture based rather than text based information and the 'picture superiority effect' describes this phenomenon (Katz et al 2006). Much of the research with pictograms and symbols used in medicine has been done with pharmaceutical agencies producing standardized pictorial symbols which depict medication-taking behaviors that help patients to comprehend medical information (Dowse and Ehlers 2001; Katz et al 2006).

Producing generic pictograms that are comprehensible to all is not easy and there is evidence that comprehensibility of some pictograms may be disease specific. In the development of a pictorial sleepiness and screening tool for obstructive sleep apnoea syndrome (OSAS), the image of 'witnessed apnoea' was better understood by those diagnosed with OSAS in contrast to those without the disease (Ghiassi et al 2007b). The use of pictograms requires care and it is not adequate to develop a representation without first testing the understanding and comprehensibility of the desired images in the appropriate population. Before images can be used with a population it is preferable to validate and test the images to ensure that both the patients and the healthcare professionals perceive the pictograms in a similar way. One validated method of testing pictograms is using Guessability and Transclucency questionnaires (Bloomberg 1990; Yovetich and Young 1988). The guessability questionnaire prompts subjects to look at each image and they are asked to record what they think it represents (Figure 1). With translucency testing, the image and word are shown together and respondents are required to rate the relationship between image and word from a score ranging from 1 to 7 , with 1 representing a poor relationship and 7 the strongest relationship (Figure 1). The two questionnaires can be used to modify and develop pictorial tools. Pictograms can be repeatedly tested and modified according to their comprehensibility by patients in whom they are likely to be used, ensuring the best representations are used for the desired tool. Using such techniques we have previously developed both a paper and an electronic version of an asthma self management plan and are currently testing a pictorial COPD self management plan (Figure 2).

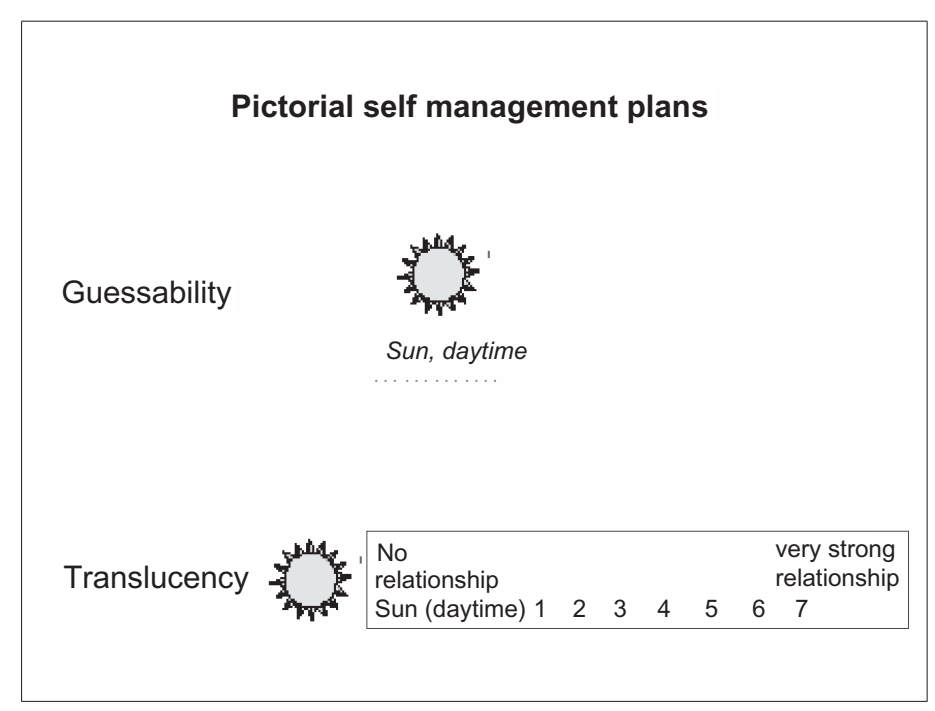

Figure I An example of an image used in guessability and translucency testing. The guessability questionnaire asks subjects to give a short meaning to the image for each image being tested. The translucency questionnaire allows subjects to review the image and the meaning and asks subject to rate the relationship between the two. The score ranges from one (no relationship) to seven (very strong relationship). Subjects are normally asked to complete the guessability questionnaire before the translucency questionnaire. 

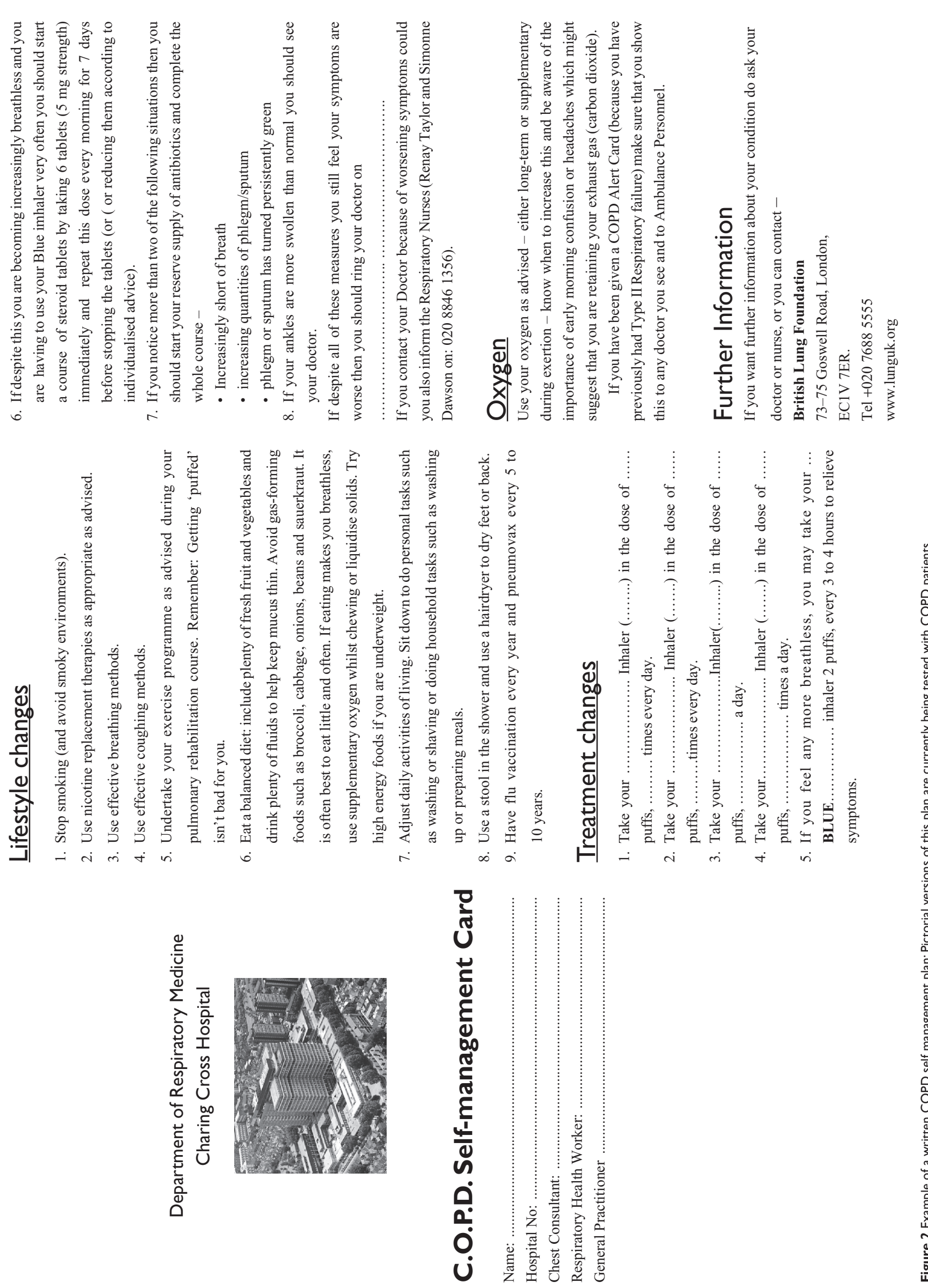
Overall, it is important that information given to patients is not "dumbed down"; it should be pitched and tailored carefully to each patient, patients with higher literacy skills should have access to more detailed information should they require it.

In summary, there are several tools or strategies available for improving the consultation to make it optimal for those with a range of literacy skills (Table 1). After the consultation, written and pictorial advice should be given to patients to reinforce advice and improve patients' ability to recall information ultimately increasing patient adherence to therapies and patient satisfaction.

\section{Summary points}

- Reduced health literacy is associated with reduced compliance and poor health outcomes

- Literacy skills in patients are difficult to assess

- Tools to assess literacy such as REALM can highlight reduced literacy but can be an embarrassing procedure for patients

You can improve recall and compliance in all patients if you:

- Give patients some information before their appointment to inform them of what will take place

- Use less jargon in your consultations

- Ask your patients questions about details you have changed during their current consultation, ie, medication "Can you tell me how often you are going to take your new inhaler (show picture to patient) when you get home?"

- Draw diagrams or give patients some key written messages to take home

- Use leaflets or pictures to reinforce any key messages you want patients to remember

- Send your patients a copy of the letter you send to their physician, but do so with a glossary of terms it may contain

\section{Disclosures}

The authors report no conflicts of interest.

\section{References}

Allen SC, Ragab S. 2002. Ability to learn inhaler technique in relation to cognitive scores and tests of praxis in old age. Postgrad Med J, 78:37-9.

Bailey WC, Richards JM Jr, Brooks CM, et al. 1990. A randomized trial to improve self-management practices of adults with asthma. Arch Intern Med, 150:1664-8.

Baker DW, 1999. Development of a brief test to measure functional health literacy. Patient Education and Counseling, 38:33-42.

Baker DW, Parker RM, Williams MV, et al. 1998. Health literacy and the risk of hospital admission. J Gen Intern Med, 13:791-8.
Baker D, Parker RM, Williams MV, et al. 1997. The relationship of patient reading ability to self-reported health and use of health services. Am J Public Health, 87:1027-30.

Beckman HB, Frankel RM. 1984. The effect of physician behaviour on the collection of data. Ann Intern Med, 101:692-6.

Bloomberg, K. 1990. The comparative translucency of initial lexical items represented in five graphic symbol systems and sets. $J$ Speech Hearing Res, 33:717-25.

Booker R. 2005. Effective communication with the patient. Eur Respir Rev, 14:93-6.

Bourbeau J, Julien M, Maltais F, et al. 2003. Reduction of hospital utilization in patients with chronic obstructive pulmonary disease: a disease-specific self-management intervention. Arch Intern Med, 163:585-91.

Brown CE, Roberts NJ, Partridge MR. 2007. Does the use of a glossary aid patient understanding of the letters sent to their general practitioner? Clin Med, 7:457-60.

Centre for Health Care Strategies. 2008. Centre for Health Care Strategies Health Literacy Factsheets [online]. Accessed 11 January. URL: http:// www.chcs.org/resource/hl.html

Cochrane GM. 1992. Therapeutic compliance in asthma; its magnitude and implications. Eur Respir J, 5:122-4.

Constantinidou F, Baker S. 2002. Stimulus modality and verbal learning performance in normal aging. Brain Lang, 82: 296-311.

Davis TC, Long SW, Jackson RH, et al. 1993. Rapid Estimate of Adult Literacy in Medicine: a shortened screen instrument. Fam Med, 25:391-5.

Davis TC, Wolf MS, Bass PF, et al. 2006. Literacy and misunderstanding prescription drug labels. Ann Intern Med, 145:887-94.

Delp C, Jones J. 1996. Communicating information to patients: the use of cartoon illustrations to improve comprehension of instructions. Acad Emerg Med, 3: 264-70.

Dowse R, Ehlers MS. 2001. The evaluation of pharmaceutical pictograms in a low-literate South African population. Patient Education and Counselling, 45: 87-99.

Dowse R, Ehlers M. 2005. Medicine labels incorporating pictograms: do they influence understanding and adherence? Patient Educ Couns, 58:63-70.

Falvo D, Tippy P. 1988. Communicating information to patients. Patient satisfaction and adherence as associated with resident skill. J Fam Pract, 26:643-7.

Gazmararian JA, Baker DW, Williams MV, et al. 1999. Health literacy among Medicare enrollees in a managed care organization. JAMA, 281:545-51.

Ghiassi R, Cummin A, Slingsby L, et al. 2007a. Can patients self-adminster the epworth sleepiness scale? Thorax, 62:A110.

Ghiassi R, Cummin A, Murphy K, et al. 2007b. The development of a pictorial screening tool to assess sleepiness and obstructive sleep apnoea syndrome. Am J Respir Crit Care Med, 175:A698.

Gordon M, Hampson R, Capell H, et al. 2002. Illteracy in rheumatoid arthritis patients as determined by the Rapid Estimate of Adult Literacy in Medicine (REALM) score. Rheumatology, 41:750-4.

Grant I, Heaton RK, McSweeny AJ, et al. 1982. Neuropsychologic findings in hypoxemic chronic obstructive pulmonary disease. Arch Intern Med, 142:1470-6.

Grant I, Prigatano GP, Heaton RK, et al. 1987. Progressive neuropsychologic impairment and hypoxemia. Relationship in chronic obstructive pulmonary disease. Arch Gen Psychiatry, 44:999-1006.

Hand C, Bradley C. 1996. Health beliefs of adults with asthma: toward an understanding of the difference between symptomatic and preventive use of inhaler treatment. $J$ Asthma, 33:331-8.

Hatcher, S. 1999. Review: incidence of dementia and Alzheimer's disease increases with increasing age. Evid Based Ment Health, 2:60.

Henderson AS, Jorm AF. 1998. Dementia in Australia. Canberra (ACT): Department of Health and Family Services; Aged and Community Care Service Development and Evaluation Report No 35.

Horne R, Weinman J. 1999. Patients' beliefs about prescribed medicines and their role in adherence to treatment in chronic physical illness. J Psychosom Res, 47:555-67. 
Houts P, Bachrach R, Witmer J, et al. 1998. Using pictographs to enhance recall of spoken medical instructions. Patient Educ Couns, 35:83-8.

Houts P, Doak C, Loscalzo M. 2006. The role of pictures in improving health communication: A review of research on attention, comprehension, recall, and adherence. Patient Educ Couns, 61:173-90.

Houts P, Witmer J, Egeth H, et al. 2001. Using pictographs to enhance recall of spoken medical instructions II. Patient Educ Couns, 43:231-42.

Jones D. 2007. Too little, too late the patients' perspective on education for COPD. Chron Respir Dis, 4:189-90.

Jorm AF. 2000. Is depression a risk factor for dementia or cognitive decline? Gerontology, 46:219-27.

Katz MG, Kripalani S, Weiss BD. 2006. Use of pictorial aids in medication instructions: a review of the literature. Am J Health Syst Pharm, 63:2391-7.

Kelly PA, Haidet P. 2007. Physician overestimation of patient literacy: a potential source of health care disparities. Patient Educ Couns, 66:119-22.

Kessler R, Stahl E, Vogelmeier C, et al. 2006. Patient understanding, detection, and experience of COPD exacerbations: an observational, interview-based study. Chest, 130:133-42

Kirsch IS, Jungeblut A, Jenkins L. 1993. Adult literacy in America: a first look at the results of the National Adult Literacy Survey. Washington, DC: National Center for Education Statistics, United States Department of Education.

Korsch BM, Negrete VF. 1972. Doctor-patient communication. Sci Am, 227: 66-74.

Krigsman K, Moen J, Nilsson JL, et al. 2007. Refill adherence by the elderly for asthma/chronic obstructive pulmonary disease drugs dispensed over a 10-year period. J Clin Pharm Ther, 32:603-11.

Kutner M, Greenberg E, Jin Y, et al. 2006. The health literacy of America's adults: results from the 2003 National Assessment of Adult Literacy (NCES 2006-483). Washington (DC): US Department of Education, National Center for Education Statistics.

Langewitz W, Denz M, Keller A, et al. 2002. Spontaneous talking time at start of consultation in outpatient clinic: cohort study. $B M J$, 325:682-3.

Ley P. 1979. Memory for medical information. Br J Soc Clin Psychol, 18:245-55

Lloyd B 1997. A randomised controlled trial of dictating the clinic letter in front of the patient. BMJ, 314(7077):347-8.

Monninkhof E, van der Valk P, van der Palen J, et al. 2003. Self-management education for patients with chronic obstructive pulmonary disease: a systematic review. Thorax, 58:394-8.

Murphy PW, Chesson AL, Walker L, et al. 2000. Comparing the effectiveness of video and written material for improving knowledge among sleep disorders clinic patients with limited literacy skills. South Med J, 93:297-304.

Oliver, SM. 2001. Living with failing lungs: the doctor-patient relationship. Fam Pract, 18:430-9.

Onyirimba F, Apter A, Reisine S, et al. 2003. Direct clinician-to-patient feedback discussion of inhaled steroid use: its effect on adherence. Ann Allergy Asthma Immunol, 90:411-5.

Osman LM, Hyland ME. 2005. Patient needs and medication styles in COPD. Eur Respir Rev, 14:89-92.

Paasche-Orlow, MK, Parker RM, et al. 2005. The Prevalence of Limited Health Literacy. J Gen Intern Med, 20:175-84.

Parikh NS, Parker RM, Nurss JR, et al. 1996. Shame and health literacy: the unspoken connection. Patient Educ Couns, 27:33-9.

Parkin T. 2003. Discrepancies between patient and professionals recall and perception of an outpatient consultation. Diabet Med, 20:909-14.

Partridge MR. 1986. Asthma education: more reading or more viewing? $J R$ Soc Med, 79:326-8.

Partridge MR. 2005. The asthma consultation: what is important? Curr Med Res Opin, 21:11-8.

Partridge M. 1999. Making effective use of limited consultation time. Asthma Journal, 4:68-73.

Plimpton S, Root J. 1994. Materials and strategies that work in low literacy health communication. Public Health Rep, 109:86-92.
Prigatano GP, Parsons O, Wright E, et al. 1983. Neuropsychological test performance in mildly hypoxemic patients with chronic obstructive pulmonary disease. J Consult Clin Psychol, 51:108-16.

Put C, van den Bergh O, Lemaigre V, et al. 2003. Evaluation of an individual asthma programme directed at behavioural change. Eur Respir $J, 21: 109-15$.

Rand CS. 2005. Patient adherence with COPD therapy. Eur Respir Rev, 14:97-101.

Roberts NJ, Partridge MR. 2006. How useful are post consultation letters to patients? BMC Med, 4:2.

Rogers ES, Wallace LS, Weiss BD. 2006. Misperceptions of medical understanding in low-literacy patients: implications for cancer prevention. Cancer Control, 13:225-9.

Sandler DA, Heaton C, Garner ST, et al. 1989. Patients' and general practitioners' satisfaction with information given on discharge from hospital: audit of a new information card. BMJ, 299:1511-3.

Schillinger D, Grumbach K, Piette J, et al. 2002. Association of Health Literacy With Diabetes Outcomes. JAMA, 288:475-82.

Schillinger D, Piette J, Grumbach K, et al. 2003. Closing the loop: physician communication with diabetic patients who have low health literacy. Arch Intern Med, 163:83-90.

Sechrest RC, Henry DJ. 1996. Computer-based patient education: observations on effective communication in the clinical setting. J Biocommun, 23:8-12.

Sridhar M, Taylor R, Dawson S, et al. 2008. A Nurse-Led intermediate care package in patients who have been hospitalised with an acute exacerbation of chronic obstructive pulmonary disease. Thorax, 63:194-200.

Taylor J, Dawson S, Sridhar M, et al. 2005. Functional illiteracy amongst those with chronic obstructive pulmonary disease (COPD). Eur Respir J, 26:57s.

Taylor R, Dawson S, Roberts N, et al. 2007. Why do patients decline to take part in a research project involving pulmonary rehabilitation? Respir Med, 101:1942-6.

The Skills for Life Survey. 2003. A national needs and impact survey of literacy, numeracy and ICT skills. Research Brief RB 490 DfES Publication.

Turnock A, Walters E, Walters J, et al. 2005. Action plans for chronic obstructive pulmonary disease. The Cochrane Database of Systematic Reviews 4, Art. No: CD005074. DOI: 10.1002/14651858.CD005074.pub2.

US Department of Health and Human Services. 2000. Healthy People 2010: Understanding and Improving Health with understanding and improving health and objectives for improving health. 2nd Ed, Washington, DC: US Government Printing Office.

van Manen, JG, Bindels PJE, Dekker FW, et al. 2002. Risk of depression in patients with chronic obstructive pulmonary disease and its determinants. Thorax, 57:412-6.

Wallace LS, Roskos SE, Weiss BD, 2006. Readability characteristics of consumer medication information for asthma inhalation devices. J Asthma, 43: 375-8.

Weiss BD, Hart G, McGee DL, et al. 1992. Health status of illiterate adults: relation between literacy and health status among persons with low literacy skills. J Am Board Fam Pract, 5:257-64

Williams MV, Baker DW, Honig EG, et al. 1998a. Inadequate literacy is a barrier to asthma knowledge and self-care. Chest, 114:1008-15.

Williams MV, Baker DW, Parker RM, et al. 1998b. Relationship of Functional Health Literacy to Patients' Knowledge of Their Chronic Disease: A Study of Patients With Hypertension and Diabetes. Arch Intern Med, 158:166-72.

Williams MV, Parker RM, Baker DW, et al. 1995. Inadequate functional health literacy among patients at two public hospitals. JAMA, 274: 1677-82.

Wolf MS, Gazmararian JA, Baker DW. 2005. Health Literacy and Functional Health Status Among Older Adults. Arch Intern Med, 165:1946-52.

Yovetich W, Young TA. 1988. The effects of representativeness and concreteness on the "Guessability" of blissymbols. Augment Altern Comm, 35-9.

Ziegler DK, Mosier MC, Buenaver M, et al. 2001. How much information about adverse effects of medication do patients want from physicians? Arch Intern Med, 161:706-13. 
